\title{
GABA $_{\mathrm{A}}$ Receptor-Mediated Inhibition of Rat Substantia Nigra Dopaminergic Neurons by Pars Reticulata Projection Neurons
}

\author{
J. M. Tepper, L. P. Martin, and D. R. Anderson \\ Center for Molecular and Behavioral Neuroscience, Aidekman Research Center, Rutgers, The State University of \\ New Jersey, Newark, New Jersey 07102.
}

Evidence from electrophysiological studies has suggested an inhibitory interaction between GABAergic neurons in substantia nigra pars reticulata and dopaminergic neurons in pars compacta. However, that this inhibitory interaction is due to a projection from pars reticulata to pars compacta has never been demonstrated directly, nor has the GABAergic neuron that mediates the interaction been identified either electrophysiologically or anatomically.

To more closely examine interactions between substantia nigra pars reticulata GABA neurons and dopaminergic neurons, single unit extracellular recordings were obtained from antidromically identified nigrostriatal neurons and their response to antidromic activation of nigral GABAergic projection neurons observed. Stimulation of superior colliculus or thalamus produced a short latency inhibition of dopaminergic neurons. This inhibition was blocked by local application of bicuculline but not 2-hydroxysacloten. Bicuculline caused most dopaminergic neurons to fire in a bursty mode, whereas saclofen caused most dopaminergic neurons to fire in a pacemaker-like mode. The thalamicevoked inhibition was not affected by kainate lesions of the globus palidus, but these lesions produced effects on firing pattern identical to those produced by saclofen.

These data demonstrate a short latency inhibition of nigral dopaminergic neurons mediated by GABA $_{A}$ receptors that arises from the axon collaterals of pars reticulata projection neurons. We propose a model in which the firing pattern of nigral dopaminergic neurons in vivo is modulated differentially by disinhibition of $\mathrm{GABA}_{\mathrm{A}}$ inputs arising from pars reticulata projection neuron axon collaterals and disinhibition of pallidonigral GABAergic inputs mediated by $\mathrm{GABA}_{\mathrm{B}}$ receptors.

[Key words: substantia nigra, dopamine, GABA, burst firing, disinhibition, extracellular recording]

The afferent control of the dopaminergic neurons of the midbrain tegmentum has generated considerable interest over the past several decades since it was discovered that these neurons were the sole source of the dopamine input to the forebrain. A

\footnotetext{
Received May 16, 1994; revised Sept. 2, 1994; accepted Nov. 2, 1994.

We thank Ms. Christine Waite for technical assistance, Ms. Sonia Guzman for secretarial help, and Drs. E. D. Abercrombie, S. F. Sawyer, and C. J. Wilson for valuable discussions and suggestions on the manuscript. This research was supported by MH-45286 and a Rutgers Research Council grant.

Correspondence should be addressed to James M. Tepper, Ph.D., Center for Molecular and Behavioral Neuroscience, Aidekman Research Center, Rutgers University, University Heights, 197 University Avenue, Newark, NJ 07102.

Copyright (C) 1995 Society for Neuroscience $0270-6474 / 95 / 153092-12 \$ 05.00 / 0$
}

dysfunction in dopaminergic neurotransmission has been implicated in the primary symptomatologies of schizophrenia and other psychoses (Creese et al., 1976) and it has been suggested that this may result from an abnormal regulation of the electrical activity of midbrain dopaminergic neurons (see Kalivas, 1993, for recent review).

It has been known for over 20 years that in vivo, midbrain dopaminergic neurons fire spontaneously in a slow, random pattern that is punctuated by short bursts of action potentials (Bunney et al., 1973). Although many studies have emphasized the role of intrinsic membrane properties to explain the rate and pattern of firing of these neurons (e.g., Grace and Bunney, 1984; Llinas et al., 1984; Kita et al., 1986; Grace, 1987; Nedergaard and Greenfield, 1992; Kang and Kitai, 1993), the fact that there are significant differences between the spontaneous activity of nigral dopaminergic neurons in vivo and in vitro (e.g., Bunney et al., 1973; Wilson et al., 1977; Kita et al., 1986; Grace, 1987) suggests that afferent input plays a large role in modulating the activity, particularly the firing pattern, of these neurons.

The best known afferents to dopaminergic neurons originate within the basal ganglia, from neostriatum (Grofová, 1975). These afferents are GABAergic (Ribak et al., 1980), and both intra- and extracellular recording studies have revealed inhibition of dopaminergic neuron activity from neostriatal stimulation (Yoshida and Precht, 1971; Grace and Bunney, 1985; Tepper et al., 1990). The entire substantia nigra stains heavily for glutamic acid decarboxylase (GAD; Ribak et al., 1976), and over $70 \%$ of all boutons synapsing on dopaminergic neurons are GABAergic (Bolam and Smith, 1990). It is somewhat surprising, then, that destruction of the neostriatum does not exert a very long-lasting or robust effect on the spontaneous activity of nigral dopamine neurons (e.g., Braszko et al,. 1981). However, not all GABAergic afferents to substantia nigra originate from striatum; there is a significant projection from globus pallidus (Hattori et al., 1975; Smith and Bolam, 1989, 1990) and stimulation of globus pallidus elicits a short latency IPSP in nigrostriatal neurons (Tepper et al., 1986, 1987). Furthermore, excitotoxin lesions of substantia nigra pars reticulata produce marked decreases in GAD activity in pars compacta (Grofová and Fonnum, 1982).

Grace and colleagues (Grace and Bunney, 1979, 1985; Grace et al., 1980) have shown that there is a reciprocal relation between the spontaneous firing of nondopaminergic neurons in the pars reticulata and dopaminergic neurons of the pars compacta. These data were interpreted to indicate that there exists a monosynaptic pathway between a population of GABAergic neurons in pars reticulata and dopaminergic neurons in pars compacta. However, since the dendrites of pars compacta dopaminergic 
neurons extend deeply into pars reticulata (Juraska et al., 1977; Tepper et al., 1987), it is difficult to stimulate pars reticulata by conventional means while recording from dopaminergic neurons without also risking a confounding direct stimulation of the dopamine neurons themselves. Thus, there have been no direct electrophysiological tests of the hypothesis.

Although the original reports did not identify the GABAergic neuron producing inhibition of the dopaminergic neurons (Grace and Bunney, 1979; Grace et al., 1980), subsequent reports (Grace and Bunney, 1985; Smith and Grace, 1992) suggested that the GABA neurons participating in this feed-forward inhibition comprised a class of "zona reticulata interneurons" existing just ventral to the pars compacta, because they could not be antidromically activated from thalamus, superior colliculus, or striatum, responded to noxious stimuli with a brief excitation, and were very sensitive to the effects of GABA. This suggestion of a class of interneurons that mediate a number of indirect effects on dopaminergic neurons has been generally accepted and widely cited by others (e.g., Mereu and Gessa, 1985; Johnson and North, 1992; Santiago and Westcrink, 1992; Zhang ct al., 1992, 1993; Cameron and Williams, 1993; Yung and Häusser, 1993). However, it is also possible that feed-forward inhibition could be mediated by local axon collaterals of the nigrocollicular and/or nigrothalamic projection neurons which ramify extensively within substantia nigra (Deniau et al., 1982; Grofová et al., 1982). This hypothesis can be tested by taking advantage of the fact that while pars reticulata neurons project to the superior colliculus and thalamus, monosynaptic projections from these areas back to the substantia nigra have not been demonstrated. Stimulation of the superior colliculus and/or thalamus would elicit antidromic action potentials in nigrocollicular and nigrothalamic neurons that would also invade axon collaterals projecting to pars compacta. In this way it is possible to drive pars reticulata projection neurons directly, without also stimulating dopaminergic pars compacta neurons. If direct projections between pars reticulata projection neurons and dopaninergic neurons exist, then such stimulation should inhibit the firing of the dopamine neurons. If, on the other hand, pars reticulata interneurons provide the bulk of the feed-forward inhibitory link to dopamine neurons, then stimulation of superior colliculus or thalamus should elicit either an excitatory response in the dopamine neurons due to a GABAergic disinhibition of the interneurons, or little or no effect if the local axon collaterals of the projection neurons do not influence the interneurons.

The present experiments were designed to (1) test electrophysiologically the hypothesis that there are direct monosynaptic connections between pars reticulata GABAergic neurons and pars compacta dopaminergic neurons, and (2) if so, to identify the GABAergic neurons participating as projection neurons or interneurons.

Portions of these data have been previously reported in abstract form (Anderson et al., 1993).

\section{Materials and Methods}

Subjects. Seventy-one male Sprague-Dawley rats (Institute of Animal Behavior, Rutgers or Zivic-Miller) weighing between 225 and $350 \mathrm{gm}$ were used in these experiments. For acute recording experiments, rats were anesthetized with urethane $(1.3 \mathrm{gm} / \mathrm{kg}$, i.p.) and installed into a stereotaxic frame. Body temperature was maintained at $37 \pm 1{ }^{\circ} \mathrm{C}$. All wound edges and contact points between the animal and the stereotaxic frame were infiltrated with lidocaine ointment $(5 \%)$ or solution $(2 \%)$. All animals and were treated in strict accordance with guidelines set forth in the USPHS manual Guide for the Care and Use of Laboratory Animals.

Stimulating and recording. After removal of the scalp, small burr holes were drilled overlying the neostriatum $(1.0 \mathrm{~mm}$ anterior to breg$\mathrm{ma}, 3.7 \mathrm{~mm}$ lateral to the midline $)$, superior colliculus $(0.5 \mathrm{~mm}$ anterior to lambda, $1.0 \mathrm{~mm}$ lateral to the midline), and the ventrolateral thalamus (5.1 $\mathrm{mm}$ anterior to lambda, $2.0 \mathrm{~mm}$ lateral to the midline) for the insertion of stimulating electrodes. Bipolar stimulating electrodes having a tip separation of approximately $150 \mu \mathrm{m}$ and in vitro impedances of approximately $10 \mathrm{~K} \Omega$, were formed from $100 \mu \mathrm{m}$ diameter enamelcoated stainless steel wires (California Fine Wire). After releasing some cerebrospinal fluid by puncturing the atlanto-occipital membrane, stimulating electrodes were lowered to appropriate depths below the cortical surface for the neostriatum $(4.0 \mathrm{~mm})$, superior colliculus $(3.0 \mathrm{~mm})$, and the ventrolateral thalamic nucleus $(6.1 \mathrm{~mm})$ and cemented in place with cyanoacrylate glue and dental cement. A recording hole approximately $3.0 \mathrm{~mm}$ in diameter was drilled above the substantia nigra at coordinates $2.1 \mathrm{~mm}$ anterior to lambda and $2.0 \mathrm{~mm}$ lateral to the midline.

Recording electrodes were fabricaled from 2.0 mmm o.d. capillary lubing (World Precision Instruments) on a Narishige vertical pipette puller and possessed in vitro impedances of approximately $20 \mathrm{M} \Omega$ when filled with $2 \mathrm{M} \mathrm{NaCl}$. The electrode impedance was lowered to between 4 and $10 \mathrm{M} \Omega$ by passing $500 \mathrm{msec} 150 \mathrm{~V}$ DC pulses (Grass stimulator, model S-48) through the electrode. In some cases micropipettes were pulled as described above and then broken back under microscopic control to yield final tip diameters of $1-2 \mu \mathrm{m}$.

Constant current electrical stimuli were generated with a Winston A-65 timer/stimulator and SC- 100 constant current stimulus isolators. Neostriatal stimuli consisted of monophasic square wave pulses of $0.2-$ $3.0 \mathrm{~mA}$ intensity and $100-500 \mu \mathrm{sec}$ duration and were delivered at a rate of $0.67 \mathrm{~Hz}$. Collicular and thalamic stimuli also consisted of square wave pulses and ranged from $0.2-2.0 \mathrm{~mA}$ at a duration of $500 \mu \mathrm{sec}$ and were delivered at a rate of $0.5-0.67 \mathrm{~Hz}$. Single unit extracellular recordings were amplified with a Neurodata IR183 preamplifier and displayed on a Tektronix 5113A storage oscilloscope. All data were recorded on magnetic tape for off-line analysis.

Dopaminergic neurons were identified by their extracellular waveforms, often characterized by a prominent notch in the initial positive phase and having a duration of $2-5 \mathrm{msec}$, slow spontaneous activity and long latency antidromic responses evoked from neostriatum that consisted mostly of initial segment only spikes (Deniau et al., 1978; Guyenet and Aghajanian 1978; Tepper et al., 1984). The antidromic nature of striatal-evoked responses was determined by collision extinction with spontaneously occurring spikes (Fuller and Schlag, 1976).

To verify the efficacy of the collicular and thalamic stimulation at antidromically driving pars reticulata projection neurons, a number of nondopaminergic pars reticulata projection neurons were similarly identified on the basis of their high firing rates (15-100 spikes/sec), narrow action potential waveforms, and short latency antidromic responses from thalamus or superior colliculus that consisted entirely of full initial segment-somadendritic spikes (Deniau et al., 1978; Guyenet and Aghajanian, 1978).

Drug administration. The selective $\mathrm{GABA}_{\mathrm{A}}$ receptor antagonist, bicuculline methiodide (Sigma, St. Louis, MO), and the selective GABA receptor antagonist, 2-hydroxysaclofen (RBI, Natick, MA), were administered locally to recorded neurons by diffusion directly through the recording micropipette as described by Steward et al., (1990). These pipettes had their tips broken as described above and were filled with bicuculline methiodide ( $20 \mathrm{mM}$ ) or 2-hydroxysaclofen $(20 \mathrm{mM})$ in $1 \mathrm{M}$ $\mathrm{NaCl}, \mathrm{pH}=7.2$. The onset of the effects of drugs administered this way was very rapid, usually less than $10 \mathrm{sec}$.

Kainic acid lesions of globus pallidus. Seven rats were anesthetized with ketamine $(80 \mathrm{mg} / \mathrm{kg})$ and xylazine $(12 \mathrm{mg} / \mathrm{kg})$ intraperitoneally and installed in a stereotaxic apparatus. After reflecting the scalp a small burr hole was drilled overlying the globus pallidus at coordinates $\mathrm{A}$ -1.0 (from brcgma), L 3.2. A 32 gaugc stainless stecl cannula attached to a $10 \mu 1$ syringe in a Harvard Apparatus syringe pump by a short length of Teflon tubing was lowered $6.0 \mathrm{~mm}$ from the surface and 0.5 $\mu l$ of kainic acid $(1.25 \mu \mathrm{g} / \mu \mathrm{l}$; Sigma, St. Louis, MO) was infused over the course of 8 min. Following infusion, the cannula was kept in place for $5 \mathrm{~min}$ and then was slowly withdrawn. Diazepam $(10 \mathrm{mg} / \mathrm{kg}$, i.m.) was administered, the wound was closed and the animals returned to their home cages for 3-6 d before recording commenced.

Data analysis. Data were analyzed off line with a Macintosh IIfx computer equipped with a National Instruments MIO16L multifunction 
A

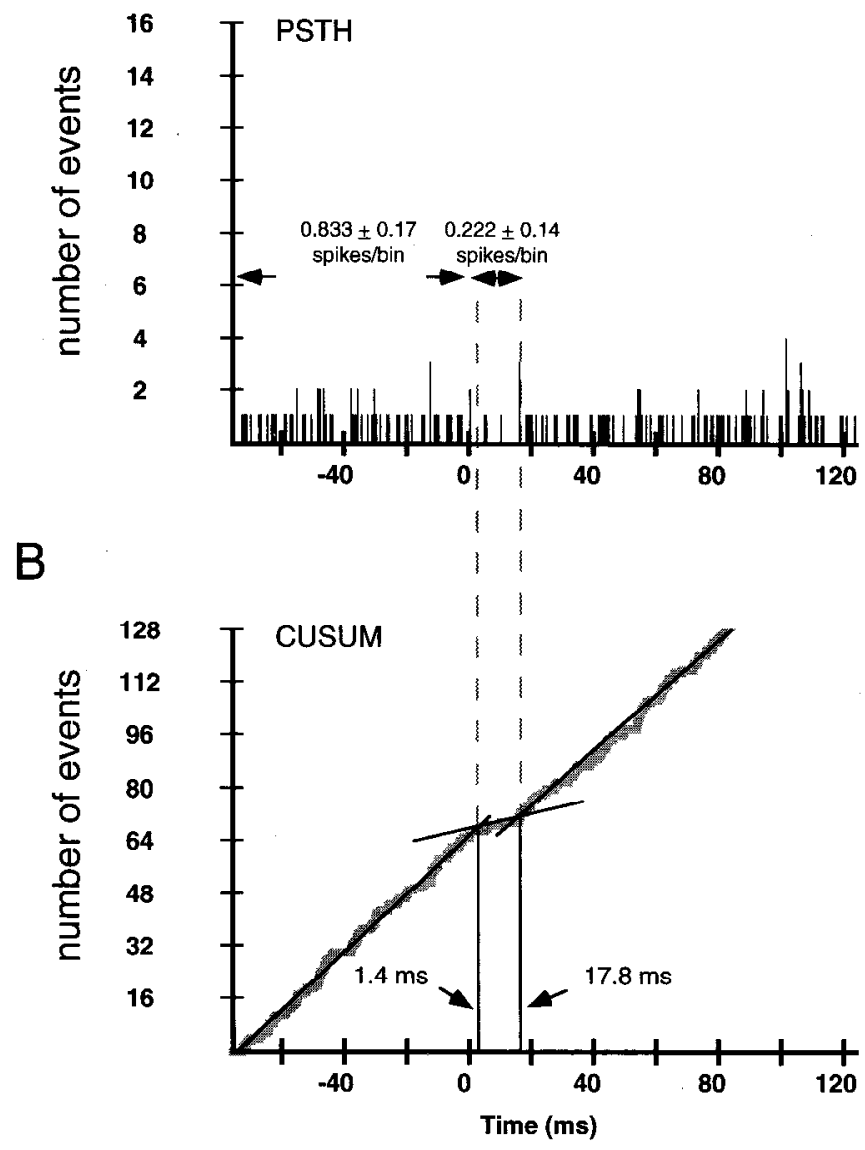

Figure 1. Method for analyzing PSTHs based on the CUSUM method of Ellaway (1977). The CUSUM histogram $(B)$ plots the cumulative sum of all preceding bins. Changes in firing rate are readily apparent by changes in the slope of the curve. To ascertain the time of onset of a stimulus-evoked effect, a straight line is fit through the prestimulus portion of the CUSUM histogram, and another through the region where the slope changes. The intersection of these two lines represents the time at which the firing rate changes, in this case, $1.4 \mathrm{msec}$ after the stimulus at time 0 . The offset of stimulus-driven effects is similarly calculated by fitting a third line to the remainder of the CUSUM histogram and the intersection of this line segment with the second line segment is the point at which the effect is no longer detectable, in this case, at $17.8 \mathrm{msec}$. These time points are then superimposed (dashed lines) on a standard PSTH constructed from the same data $(A)$ and a cursor driven measurement system is used to calculate the mean number of spikes per bin during the prestimulus baseline period and again over the duration of the stimulus effect defined by the CUSUM. In this example, the baseline firing rate was $0.833 \pm 0.17$ spikes per second and the stimulus reduced the firing rate to $0.222 \mathrm{spikes} / \mathrm{sec}$, representing a decrease in firing rate to $26.6 \%$ of control.

board. Orthodromic responses evoked from collicular and/or thalamic stimulation were characterized by measuring the magnitude and duration of inhibitory and excitatory responses from peristimulus histograms (PSTH) and cumulative sum histograms (CUSUMs; see Ellaway, 1977) generated from spike trains. Changes in the slope of CUSUMS were used to delineate the onset, offset and duration of stimulus-evoked effects as detailed in Figure 1. The average firing rate during the interval so defined was calculated by dividing the average number of spikes per bin during this interval by the prestimulus baseline activity. In addition, the peak magnitude of the inhibition was similarly calculated. Data were analyzed with analysis of variance and differences between individual groups were tested with Scheffe's $F$ test at the $p<0.1$ level of significance (Myers, 1972).

For analysis of spontaneous firing patterns of dopaminergic neurons, discriminated spike trains were examined and autocorrelograms were constructed from the spike trains as described in detail by Groves et al. (1978). Autocorrelograms were classified into one of three types: pacemaker, random, or bursty. Cells that exhibited three or more equally spaced peaks (times of significantly increased firing probability) in the autocorrelogram were defined as pacemakers, cells that exhibited an initial peak followed by a decay to a steady state were classified as bursty, and the remainder were classified as random. The number of peaks in the autocorrelogram which occur at integral multiples of the mean interspike interval represents an additional quantitative index of the regularity of firing. To further quantify bursty firing, the computer was programmed to detect bursts, defined as starting with the first interspike interval of $80 \mathrm{msec}$ or less and terminating with the first interspike interval of $160 \mathrm{msec}$ or greater (Grace and Bunney, 1984). The fraction of all action potentials that occurred in bursts for each neuron was calculated by dividing the number of spikes within bursts by the total number of spikes recorded for each neuron. Unless otherwise specified, all values are expressed as the mean \pm SEM.

Histology. At the end of each experiment, small lesions were created at the stimulating sites by passing $500 \mu \mathrm{A}$ direct current through each stimulating electrode for 1-2 sec. A lethal dose of urethane was administered and animals were perfused transcardially with a saline rinse followed by $10 \%$ buffered formalin or $4 \%$ paraformaldehyde and $0.2 \%$ glutaraldehyde in $0.15 \mathrm{M}$ phosphate buffer. Brains were postfixed, sectioned, and stained with neutral red for histological verification of stimulating sites and kainic acid lesions.

\section{Results}

\section{Neuronal identification}

The data in this report are comprised of recordings from 167 neurons presumed to be dopaminergic neurons. Of these, 113 neurons were antidromically activated from ipsilateral neostriatum with characteristics that identify them conclusively as dopaminergic nigrostriatal neurons, as illustrated for a representative neuron in Figure $2 A$. These include long latency (14.8 \pm $0.4 \mathrm{msec}$ ) antidromic responses consisting mostly of the initial segment spike only (Guyenet and Aghajanian, 1978), which often occurred at multiple, discrete latencies (Collingridge et al., 1980; Tepper et al., 1984). The remaining 54 neurons could not be antidromically driven from neostriatum, but displayed other characteristics such as slow spontaneous firing rate and a long duration action potential with a notch on the initial positive component (corresponding to an initial segment-somatodendritic break) that are generally accepted as belonging to nigral dopaminergic neurons (Bunney et al., 1973; Guyenet and Aghajanian, 1978). As there were no significant differences in spontaneous firing rate, distributions of firing pattern, or responses to thalamic or collicular stimulation between the neurons that were antidromically activated from neostriatum and those that were not, the data were combined into a single group assumed to represent nigral dopaminergic neurons.

In addition, recordings were obtained from 229 nondopaminergic pars reticulata neurons. Of these, 94 were antidromically activated from ipsilateral, thalamus at a latency of $2.37 \pm 0.12$ msec and 25 were antidromically activated from ipsilateral superior colliculus at a latency of $2.21 \pm 0.27 \mathrm{msec}$. Examples of antidromic activation of nigrothalamic and nigrocollicular neurons are shown in Figure $2, B$ and $C$.

\section{Effects of thalamic and collicular stimulation on dopaminergic neuron firing}

Stimulation of thalamus or superior colliculus at currents ranging from $0.5 \mathrm{~mA}$ to $2.0 \mathrm{~mA}$ consistently produced a short latency inhibition of dopaminergic neurons, as illustrated for 2 typical neurons in Figure 3. There were no significant differences among the duration or magnitude of inhibition produced by these different currents. For ease of statistical analysis, all the stimu- 
lation data reported in this paper were obtained at a current of $1.0 \mathrm{~mA}$. The firing of 32 out of 33 dopaminergic neurons tested was suppressed by thalamic stimulation to $41.6 \pm 5.0 \%$ of prestimulus baseline firing. The mean duration of the inhibition was $19.9 \pm 2.1 \mathrm{msec}$. Similarly, the firing of 26 out of 29 dopaminergic neurons tested was suppressed by collicular stimulation to $58 \pm 5.8 \%$ of the prestimulus baseline. The mean duration of the collicular-evoked inhibition was $19.9 \pm 2.8 \mathrm{msec}$.

The onset latency to the inhibition from both superior colliculus and thalamus, measured from CUSUM histograms as described in the methods section using a bin size of $0.2 \mathrm{msec}$, was estimated to be $2.8 \pm 0.62 \mathrm{msec}(n=33)$ for thalamic stimulation and $1.7 \pm 0.24 \mathrm{msec}(n=29)$ for collicular stimulation. These values are not significantly different from the antidromic latencies of pars reticulata neurons from thalamus or superior colliculus, respectively. Although the initial response to both thalamic and collicular stimulation was always an inhibition, the inhibition was occasionally followed by a rebound excitation. Initial or pure facilitation was never observed.

Effects of bicuculline on responses of dopaminergic neurons to thalamic and collicular stimulation

The use of recording pipettes containing $20 \mathrm{~mm}$ bicuculline methiodide in $1 \mathrm{M} \mathrm{NaCl}$ completely abolished inhibitory responses to both thalamic ( $n=9$ neurons) and collicular $(n=$ 10 neurons) stimulation, as shown for two representative neurons in Figure 4. In contrast to recordings obtained with control (1 $\mathrm{M} \mathrm{NaCl}$ ) pipettes, a pure facilitation was often observed at short latency, particularly in response to thalamic stimulation. All nine neurons responded to thalamic stimulation with facilitation (132 $\pm 2.7 \%$ of prestimulus baseline; see representative example in Fig. $4 B_{2}, B_{2}$ ) and 7 of 10 cells responded to collicular stimulation with facilitation (overall effect, $199.8 \pm 60.6 \%$ of prestimulus baseline). The responses to thalamic and collicular stimulation were significantly different from those obtained with control micropipettes (thalamus: $F=16.93$, df $=3,52, p<$ 0.05 ; superior colliculus: $F=12.55$, df $=3,36, p<0.05$ ).

\section{Effects of 2-hydroxysaclofen on responses of dopaminergic} neurons to thalamic and collicular stimulation

In marked contrast to the effects of bicuculline, blockade of $\mathrm{GABA}_{\mathrm{B}}$ receptors with 2-hydroxysaclofen failed to abolish the inhibitory effects of collicular or thalamic stimulation on nigral dopaminergic neurons as illustrated in Figure 5. When dopaminergic neurons were recorded with micropipettes containing $20 \mathrm{~mm}$ 2-hydroxysaclofen, eight neurons tested were inhibited by thalamic stimulation to $36.1 \pm 7.4 \%$ of prestimulus baseline and eight neurons tested were inhibited by collicular stimulation to $46.0 \pm 8.7 \%$ of prestimulus baseline. Neither of these values is significantly different from the corresponding values obtained with control saline micropipettes.

\section{Effects of pallidal lesions on responses of dopaminergic neurons to thalamic stimulation}

To demonstrate that the inhibition following thalamic stimulation was not due to antidromic activation of pallidothalamic neurons that send axon collaterals to dopaminergic neurons (e.g., Carter and Fibiger, 1978; Harnois and Filion, 1980), unilateral lesions of the globus pallidus were produced in seven rats by infusion of $0.5 \mu \mathrm{l}$ of kainic acid $(1.25 \mu \mathrm{g} / \mu \mathrm{l})$. Recordings of dopaminergic neurons were obtained $3-6 \mathrm{~d}(n=14$ cells) after kainate injection. In all 14 of the neurons recorded ipsilateral to kainate
A

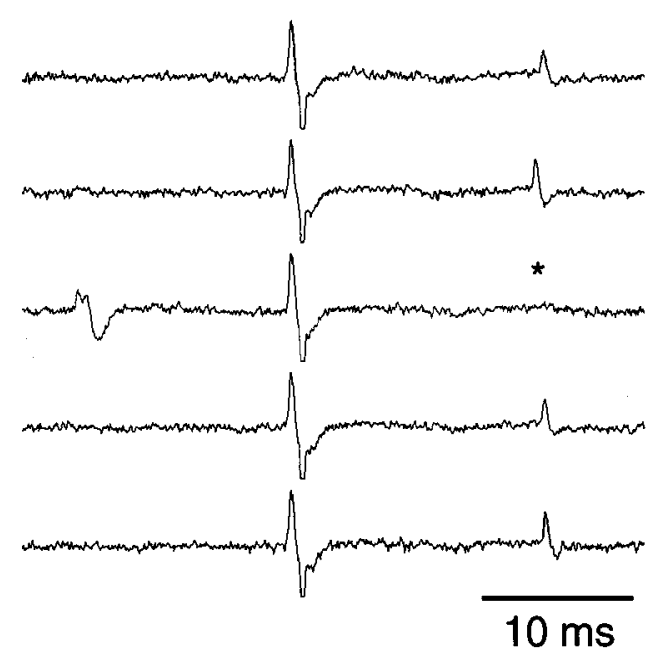

B

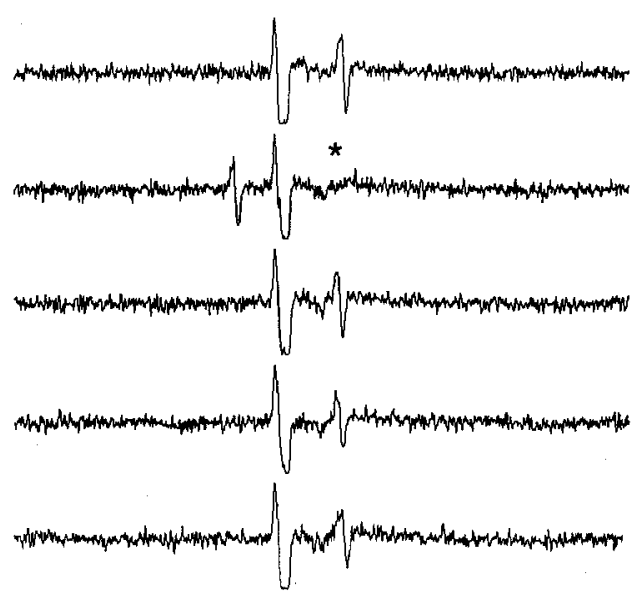

$4 \mathrm{~ms}$

C

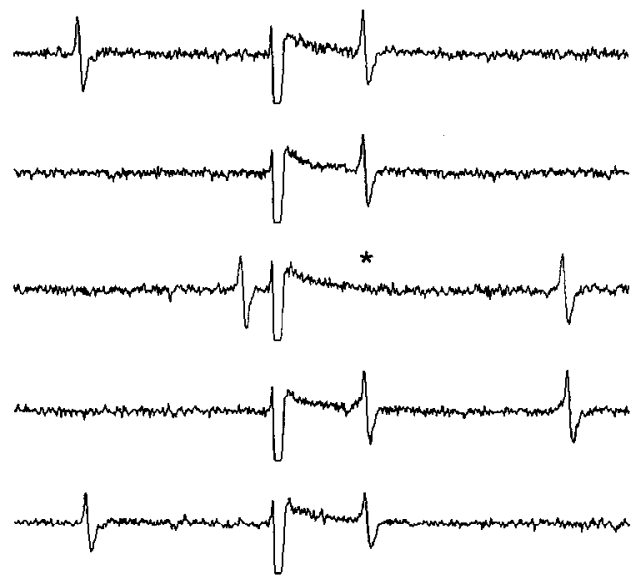

Figure 2. Antidromic identification of representative dopaminergic nigrostriatal neuron $(A)$, GABAergic nigrothalamic neuron $(B)$, and GABAergic nigrocollicular neuron $(C)$. Note that all antidromic responses of the nigrostriatal neuron consist of initial segment spikes only, whereas the spontaneous spike, and all spikes from the two pars reticulata projection neurons consist of a full initial segment-somatodendritic spike. Asterisk denotes antidromic spike missing due to collision with spontaneous action potential. Lower calibration bar applies to $B$ and $C$. Positivity is upward. 
$\mathrm{A}_{1}$

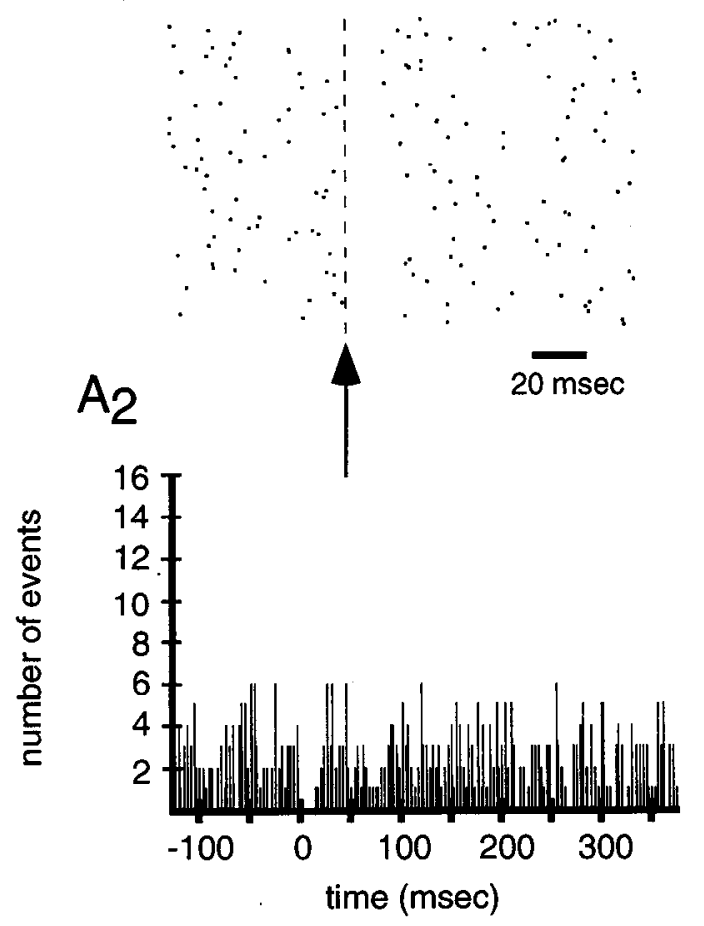

$\mathrm{B}_{1}$

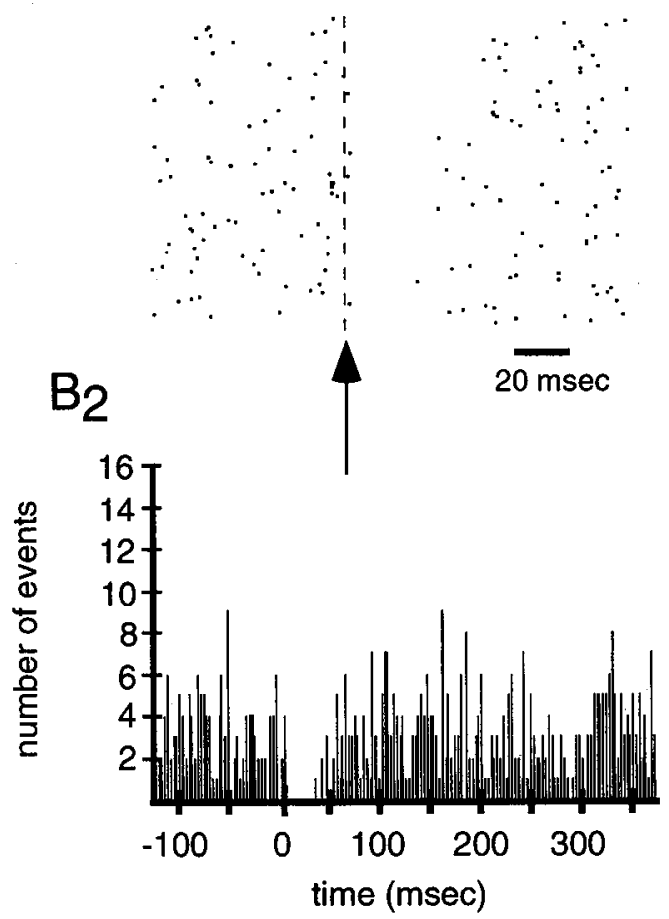

Figure 3. Inhibitory effects of thalamic and collicular stimulation on representative nigrostriatal ncurons. Stimulation (1 mA, $500 \mu s e c$ duration at arrow) of superior colliculus $(A)$ or thalamus $(B)$ produces a short latency inhibition of antidromically identified nigrostriatal dopaminergic neurons. $A$, and $B$, Raster displays of the first 140 trials for each neuron showing the inhibitory period surrounding the stimulus at high resolution. Arrow pointing to dashed lines indicates stimulus. $A_{2}$ and $B_{2}$, Peristimulus-time histograms of the neurons shown in $A_{1}$ and $B_{1}$ composed of 200220 consecutive trials of single pulse stimuli $(1 \mathrm{~mA}, 500 \mu \mathrm{sec})$ delivered to the thalamus or superior colliculus at $0.67 \mathrm{~Hz}$ at time 0 . Bin width, 3 msec. Note different time scales in the rasters and PSTHs.
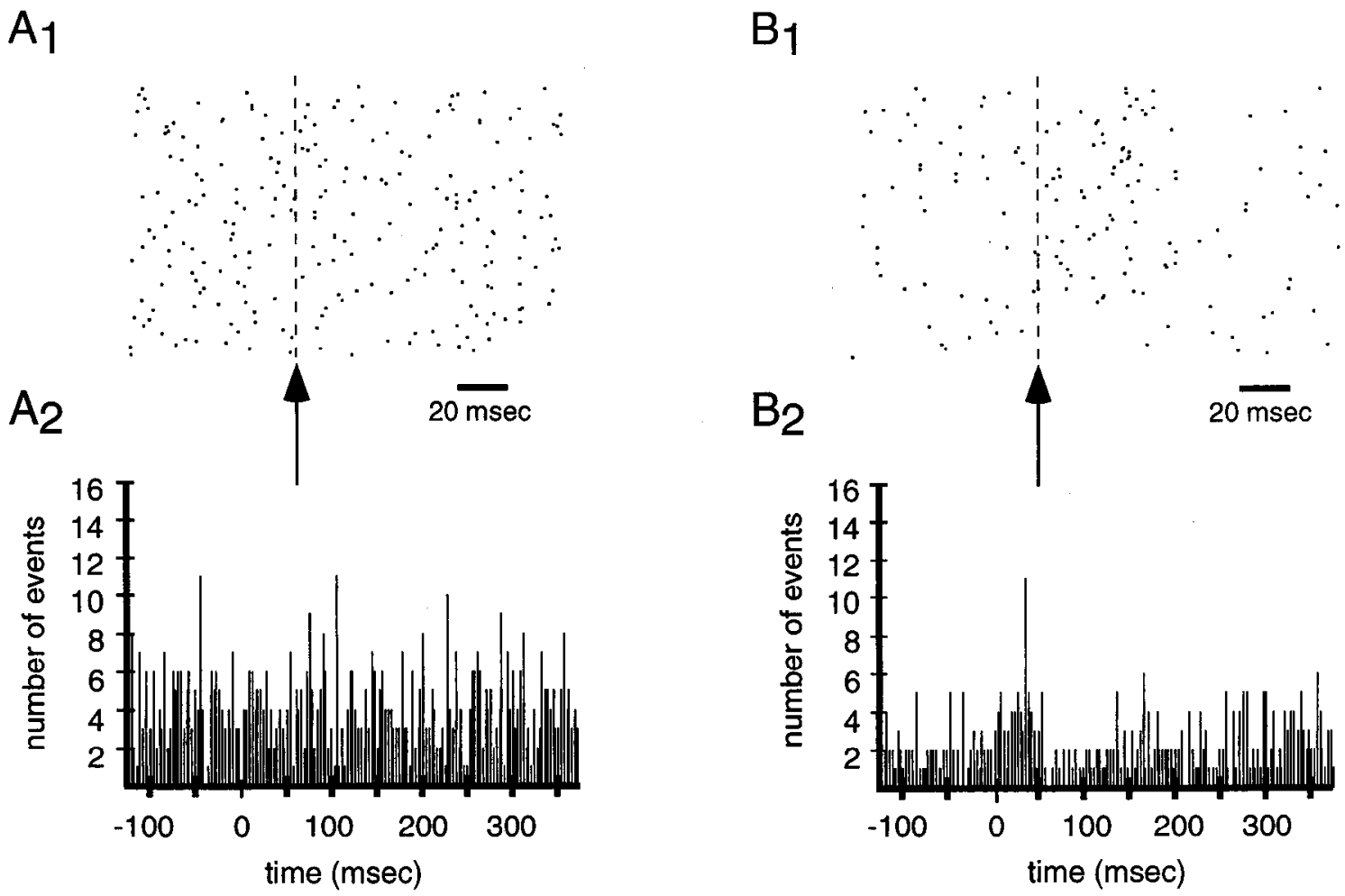

Figure 4. Effects of local application of bicuculline on responses of nigral dopaminergic neurons to thalamic or collicular stimulation. Recording with pipettes containing $1 \mathrm{M} \mathrm{NaCl}+20 \mathrm{~mm}$ bicuculline methiodide completely blocked the inhibitory effects of thalamic $(A)$ or collicular $(B)$ stimulation. Note the short latency excitation following thalanic stimulation that is unmasked by bicuculline in $B . A_{l}, A_{2}, B_{l}$, and $B_{2}$ as described in Figure 1. 
$A_{1}$

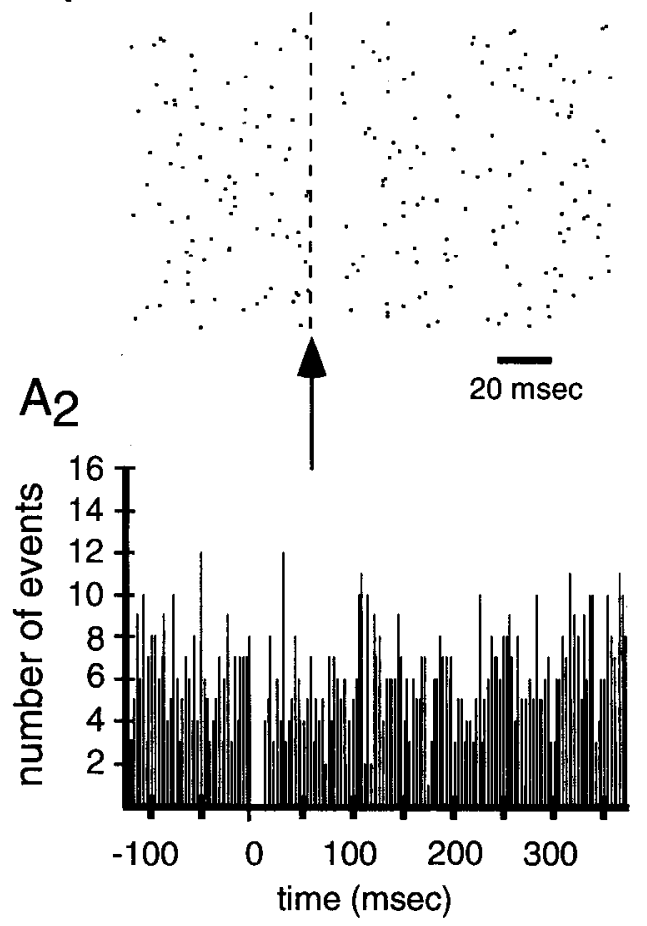

$\mathrm{B}_{1}$

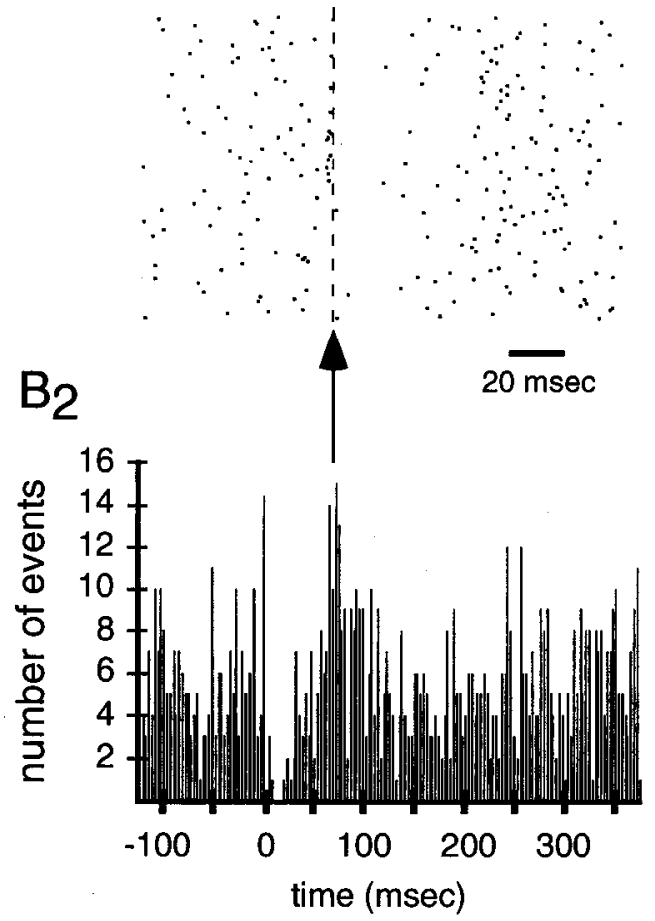

Figure 5. Effects of local application of 2-hydroxysaclofen on responses of nigral dopaminergic neurons to thalamic or collicular stimulation. Recording with pipettes containing $1 \mathrm{M} \mathrm{NaCl}+20 \mathrm{~mm}$ 2-hydroxysaclofen failed to block the inhibitory effects of either thalamic $(A)$ or collicular $(B)$ stimulation. $A_{l}, A_{2}, B_{I}$, and $B_{2}$ as described in Figure 1 .

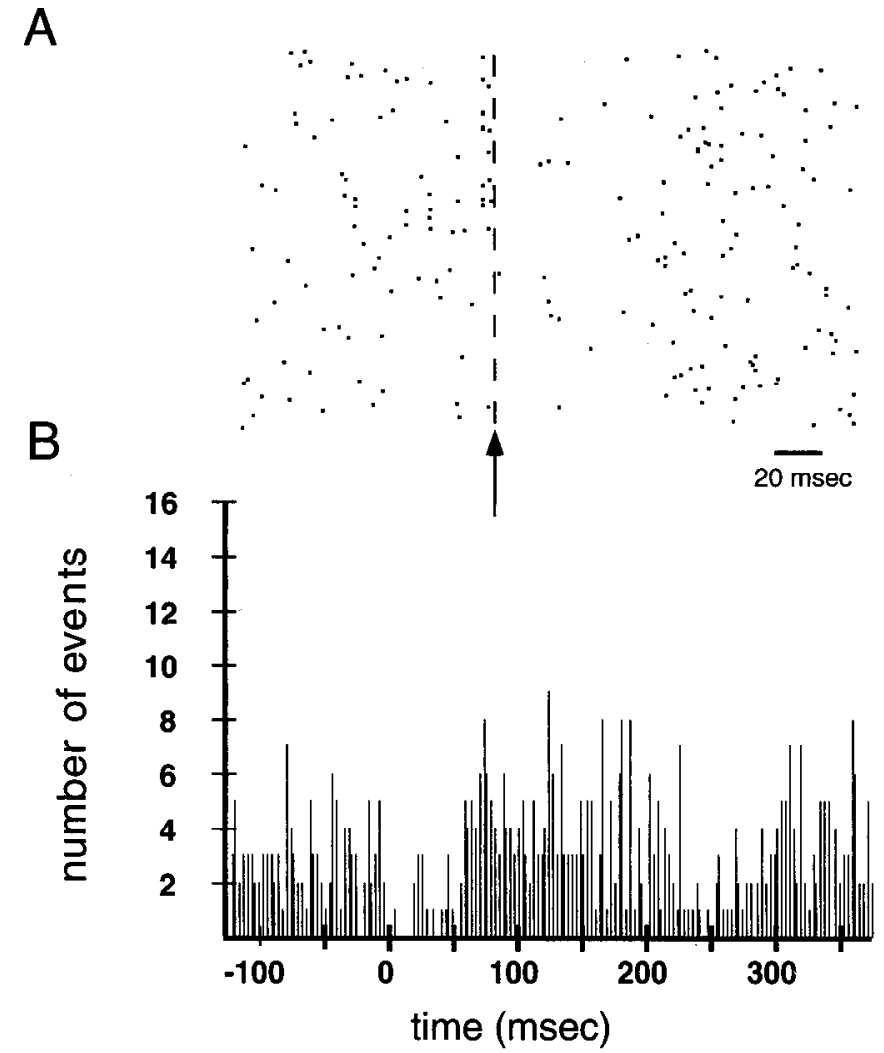

Figure 6. Effects of pallidal lesion on thalamic-evoked inhibition of nigrostriatal neurons. Kainate lesion of globus pallidus $4 \mathrm{~d}$ prior to recording does not affect inhibition of this representative nigrostriatal dopaminergic neuron evoked by thalanic stimulation. $A$ and $B$ as described in Figure 1. infusion, stimulation of the thalamus produced inhibition that was indistinguishable from that obtained in intact control rats, as illustrated for one representative neuron in Figure 6 below. In these animals, thalamic stimulation suppressed firing to 41.1 $\pm 6.8 \%$ of prestimulus baseline.

\section{Effects of bicuculline and saclofen on firing patterns of dopaminergic neurons}

The effects of bicuculline and saclofen on the firing pattern of dopaminergic neurons were quantified by measuring the proportion of spikes that occurred in bursts and by constructing autocorrelograms of spontaneous activity from ncurons recorded with pipettes containing $\mathrm{NaCl}, \mathrm{NaCl}+20 \mathrm{~mm}$ bicuculline and $\mathrm{NaCl}+20 \mathrm{~mm}$ 2-hydroxysaclofen. The most common pattern of spontaneous activity of nigrostriatal dopaminergic neurons in urethane-anesthetized rats is a random pattern, illustrated in the autocorrelation in the Figure $7 A$ (center). Pacemaker-like regular firing, illustrated in Figure $7 A$ (left), and burst firing, illustrated in Figure $7 A$ (right) are less common. As shown in Figure $7 B$, more than $56 \%$ of dopaminergic neurons recorded with control pipettes fired in a random pattern, while only $5 \%$ fired in the bursty mode and $39 \%$ in the pacemaker mode. Overall, control neurons fired $4.5 \pm 1 \%$ of their spikes in bursts. Blockade of $\mathrm{GABA}_{\mathrm{A}}$ receptors by bicuculline shifted the distribution such that more than $90 \%$ of the cells fired in the burst mode with the remainder in the random mode. Overall, cells treated with bicuculline fired $50.9 \pm 6 \%$ of their spikes in bursts.

In marked contrast to the effects of bicuculline, blockade of GABA $_{B}$ receptors by 2-hydroxysaclofen did not produce bursting but instead appeared to shift the distribution of firing patterns in the opposite direction resulting in $62 \%$ of the neurons firing 
Pacemaker Firing Mode

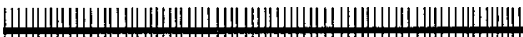
|

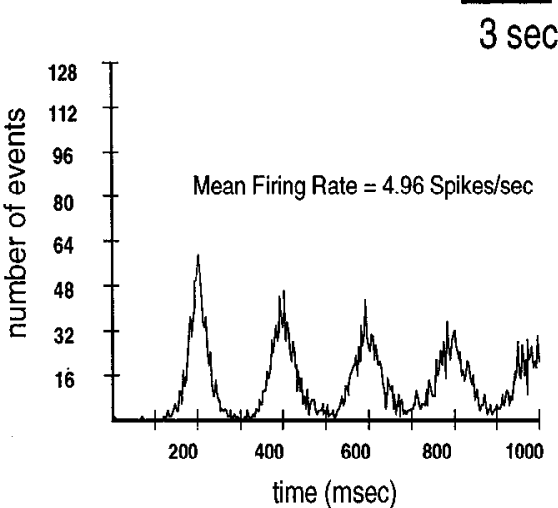

Random Firing Mode

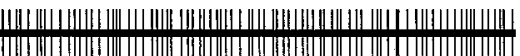

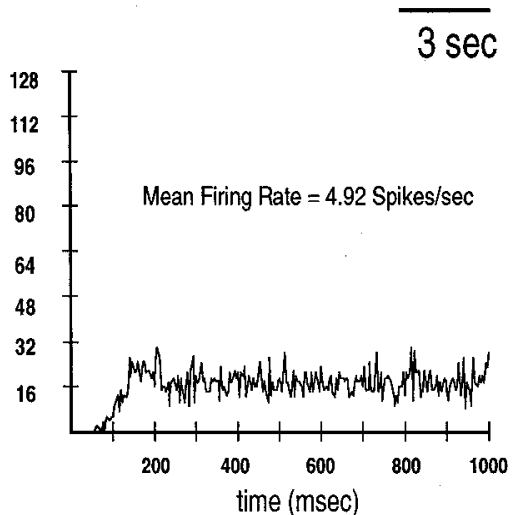

Bursty Firing Mode

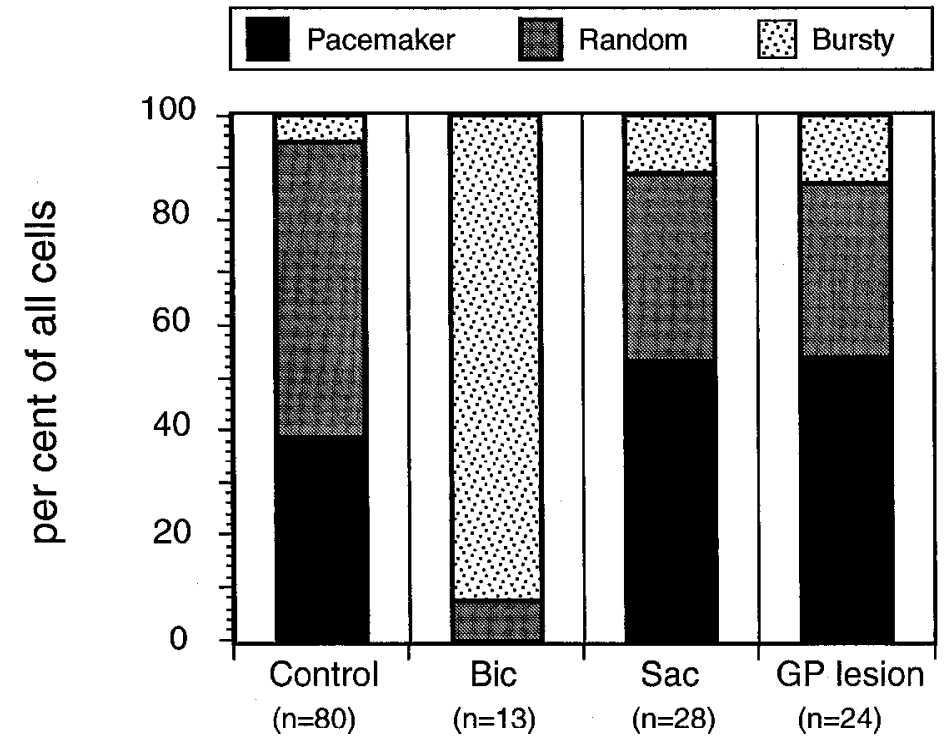

Figure 7. Effects of bicuculline and 2-hydroxysaclofen on patterns of spontaneous activity of dopaminergic neurons. A, Autocorrelograms of representative neurons exhibiting the three firing modes of dopaminergic neurons in vivo. Above each autocorrelogram is the first approximately $15 \mathrm{sec}$ of the spike train used to create the autocorrelogram. The pacemaker firing neuron was obtained with a 2-hydroxysaclofen micropipette, the random firing neuron with a saline micropipette, and the bursty firing neuron with a bicuculline micropipette. Bin width, $3 \mathrm{msec} . B$, Summary graph of the distribution of firing patterns recorded with control ( $1 \mathrm{M} \mathrm{NaCl}$ ), Bic (1 M NaCl +20 InM bicuculline Inethiodide), or Sac (1 IIIM NaCl $+20 \mathrm{~mm}$ 2-hydroxysaclofen) micropipettes, or with control micropipettes following kainic acid lesion of the ipsilateral globus pallidus.

in the pacemaker mode and only $28 \%$ of the cells in the random mode. Overall, cells treated with saclofen fired $8.1 \pm 4 \%$ of their spikes in bursts. These alterations in the distribution of firing pattern were statistically significant $\left(\chi^{2}=52.9, \mathrm{df}=9, p\right.$ $<0.05$ ).

The number of peaks in the autocorrelograms of the pacemaker-mode neurons was also counted. This revealed that not only was the distribution of firing patterns altered, but that those neurons firing in the pacemaker pattern tended to become even more regular under the influence of saclofen. Pacemaker neurons in the control condition exhibited an average of $5.67 \pm 0.58$ peaks $(n=33)$, while those recorded in the presence of saclofen had $7.67 \pm 1.5$ peaks $(n=15)$. No corresponding measurement could be made for bicuculline-treated neurons since none of these exhibited a pacemaker-like firing pattern.
These alterations in firing pattern were accompanied by less dramatic, but statistically significant increases in spontaneous firing rate $(F=4.71, \mathrm{df}=3,143, p<0.05)$ The mean firing rate of dopamine neurons recorded with control micropipettes was $3.80 \pm 0.16$ spikes $/ \mathrm{sec}(n=80)$. With $20 \mathrm{~mm}$ bicuculline in the pipette the mean firing rate was $4.76 \pm 0.39$ spikes $/ \mathrm{sec}$ $(+25.3 \% ; n-16)$ and with 2-hydroxysaclofen it was $4.92 \pm$ 0.40 spikes/sec $(+29.5 \% ; n=24)$. Of these values, only that for 2-hydroxysaclofen was significantly different from the controls.

\section{Effects of pallidal lesions on the firing patterns of} dopaminergic neurons

Similar to the effects of the $\mathrm{GABA}_{\mathrm{B}}$ antagonist, 2-hydroxysaclofen, kainic acid lesions of the globus pallidus led to an increase 
in the proportion of dopaminergic neurons that exhibited a very regular, pacemaker-like firing pattern, and a decrease in the proportion of neurons firing in the random mode as shown in Figure 7. The number of peaks in the autocorrelograms of the pacemaker neurons from globus pallidus lesion group (8.46 \pm 1.1 ; $n=13$ ) was significantly greater than those in the salinc control group $(p<0.05)$. Despite this effect on the distribution of firing pattern, globus pallidus lesions did not have any effect on mean firing rate $(3.72 \pm 0.32$, for the lesion group vs $3.80 \pm 0.16$ for the controls).

\section{Effects of bicuculline and saclofen on firing rate of nigrocollicular and nigrothalamic neurons}

In contrast to dopaminergic neurons in which the GABA antagonists only increased firing rate by $25-30 \%$, GABAergic pars reticulata projection neurons exhibited a very dramatic increase in firing in response to bicuculline and 2-hydroxysaclofen $(F=$ 9.19 , df $=2,30, p<0.05$ ). Control neurons fired at a rate of $28 \pm 4.2$ spikes per second $(n=10)$. Bicuculline-treated neurons fired at $76.2 \pm 10.8$ spikes per second $(+168 \% ; n=12)$ and 2-hydroxysaclofen-treated neurons fired at $49.5 \pm 5.6$ spikes per second $(+72.3 \% ; n=11)$. The firing rates for both bicuculline- and saclofen-treated cells were significantly different from those recorded with control micropipettes $(F=9.19$, $\mathrm{df}=2,30, p<0.05$ ).

\section{Discussion}

Effects of activation of pars reticulata GABAergic projection neurons on dopaminergic neurons

The principal aim of this study was to test the hypothesis that there is a direct connection between pars reticulata GABAergic neurons and dopaminergic neurons, and to attempt to identify the GABA neuron participating in the interaction. Antidromic activation of pars reticulata projection neurons from thalamus or superior colliculus resulted in a fast onset $(\sim 2.5 \mathrm{msec})$ inhibition of dopaminergic neurons that persisted after destruction of the globus pallidus. This latency is not significantly longer than the antidromic conduction time from thalamus or superior colliculus to substantia nigra reported here and elsewhere (e.g., Deniau et al., 1978; Guyenet and Aghajanian, 1978), strongly suggesting that the inhibition results from activation of a monosynaptic projection from substantia nigra pars reticulata. This conclusion is consistent with recent reports that IPSPs can be elicited in dopaminergic neurons by local stimulation of pars reticulata in vitro (Hajós and Greenfield, 1993; Yung and Hässer, 1993) and that this response persists in brain slices after sectioning of descending GABA pathways from the forebrain (Hajós and Greenfield, 1994). The fact that almost all dopaminergic neurons tested were inhibited by collicular or thalamic stimulation suggests that axon collateral projections from nigrothalamic and nigrocollicular neurons represent an important and ubiquitous afferent input to nigral dopaminergic neurons.

There is also anatomical support for the proposal that pars reticulata GABAergic projection neurons synapse on dopaminergic neurons. Intracellular labeling studies with HRP revealed that reticulata projection neurons possess local axon collaterals that arborize within both pars compacta and pars reticulata (Grofová et al., 1982) and a number of GABAergic synapses remain in substantia nigra after severing the both the striatonigral and pallidonigral inputs (Nitsch and Riesenberg, 1988). A recent study of antidromically identified pars reticulata nigrothalamic neurons intracellularly labeled with biocytin demonstrated that these neurons send axon collaterals to pars compacta that issue large boutons and make repeated symmetric contacts with the proximal dendrites and cell bodies of pars compacta dopaminergic neurons (Damlama et al., 1993).

\section{Nigral interneurons}

The existence of a small GABAergic neuron in substantia nigra, presumed to be an interneuron, has been inferred from anatomical (e.g., Gulley and Wood 1970; Schwyn and Fox, 1974; Juraska et al., 1977; Francois et al., 1979) and electrophysiological (Wilson et al., 1977; Matsuda et al., 1987; Yung et al., 1993) evidence. However, relatively little is known about the afferent and efferent connections of this neuron, or whether it is, in fact, an interneuron.

Although cross-correlation evidence of inhibitory interactions between presumed interneurons and pars reticulata projection neurons has been obtained in vivo, similar interactions between presumed interneurons and dopaminergic neurons were not reported (Wilson et al., 1977). Others have shown that the excitatory effects of opioids on ventral tegmental area dopaminergic neurons in vitro are mediated indirectly, through a nondopaminergic neuron presumed to be an interneuron (Lacey et al., 1989; Johnson and North, 1992; Lacey, 1993).

Freeman and Zhang (1993) reported that nigrothalamic neurons were excited by toe pinch, indicating that an excitatory response to noxious stimuli may not be a reliable criterion for distinguishing pars reticulata interneurons from projection neuron as suggested by Grace and Bunney $(1979,1985)$. In the present study, GABA receptor antagonists increased the mean spontaneous firing rate of pars reticulata projection neurons by $75-170 \%$, while the same manipulation only increased the mean firing rate of dopaminergic neurons by $25-30 \%$, suggesting that pars reticulata projection neurons are much more sensitive to the effects of GABA then dopaminergic neurons, as were the putative interneurons described by Grace and Bunney (1979, 1985).

Although no evidence could be found to suggest that GABAergic interneurons play a significant role in controlling the activity of nigral dopaminergic neurons in the present study, our results do not rule out a such a role for nigral interneurons, and Yung et al. (1991) intracellularly labeled large neurons in pars compacta with in vitro electrophysiological properties distinct from both dopaminergic neurons and pars reticulata projection neurons. However, if GABAergic interneurons exist, and do form synapses on dopaminergic neurons, their inputs must be largely restricted to extrinsic afferents to substantia nigra and not predominantly from collaterals of the GABAergic projection neurons. This is illustrated in the wiring schematics below. In Figure $8 A$, an interneuron is shown synapsing on the dopamine neuron but not receiving input from a pars reticulata projection neuron. In this case, antidromic activation of pars reticulata projection neurons would not affect the firing of dopaminergic neurons. If the local collaterals of the projection neuron synapse on an inhibitory interneuron as illustrated in Figure $8 B$, then antidromic activation of the projection neuron would produce a facilitation of firing of the dopaminergic neuron through disinhibition of the interneuron. However, neither of these two results was obtained. Rather, stimulation of thalamus or superior colliculus reliably inhibited nigral dopaminergic dopamine neurons. Although these results do not rule out the possibility that some pars reticulata GABAcrgic interncurons may contact dopaminergic neurons, they demonstrate that such an arrangement can- 

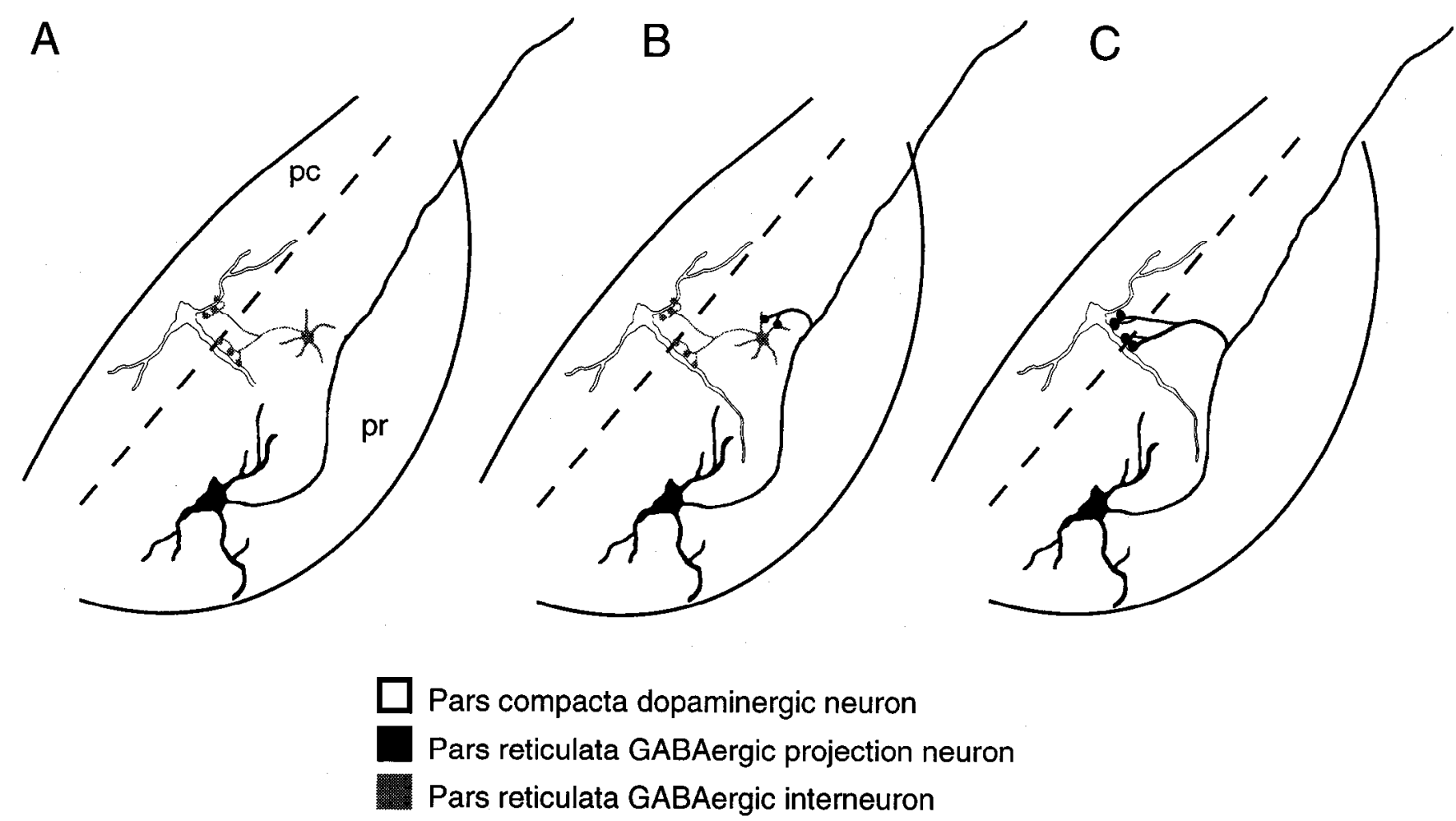

Figure 8. Simplified schematic diagram illustrating three modes of interaction between substantia nigra pars reticulata GABAergic projection neurons and, interneurons and dopaminergic neurons. In $A$, antidromic activation of pars reticulata GABAergic output neurons would have no effect on dopaminergic nigrostriatal neuron firing. In $B$, antidromic activation of pars reticulata output neurons would lead to increased firing of dopaminergic nigrostriatal neuron firing due to disinhibition of an inhibitory interneuron. In $C$, antidromic activation of pars reticulata output neurons would inhibit dopaminergic nigrostriatal neuron firing.

not be the only, or even the predominant, way in which pars reticulata neurons inhibit dopaminergic neurons. Rather, this interaction appears to be mediated to a significant extent by a direct monosynaptic connection between pars reticulata projection neurons and dopaminergic neurons, illustrated in Figure $8 C$.

Differential effects of $G A B A_{A}$ and $G A B A_{B}$ antagonists on evoked responses and spontaneous activity of dopaminergic neurons

The inhibitory responses of dopaminergic neurons to antidromic activation of nigrothalamic or nigrocollicular neurons was blocked by the $\mathrm{GABA}_{\mathrm{A}}$ antagonist, bicuculline. In contrast, the $\mathrm{GABA}_{\mathrm{B}}$ antagonist, 2-hydroxysaclofen, did not affect inhibition in dopaminergic neurons evoked by the same stimuli. These results demonstrate that the inhibition arising from pars reticulata projection neurons is GABAergic in nature, and that it is mediated primarily or exclusively by $\mathrm{GABA}_{\mathrm{A}}$ receptors.

A short-latency facilitation of firing was often observed in dopaminergic neurons following stimulation of thalamus or superior colliculus in the presence of bicuculline. The origin(s) of this excitatory response remains uncertain, but projections from both the thalamus (Sugimoto et al., 1983) and the superior colliculus (Tokuno et al., 1994) to the subthalamic nucleus have been identified. The subthalamic nucleus projects to the substantia nigra (Kita and Kitai, 1987), where approximately $90 \%$ of subthalamic boutons synapse on nondopaminergic dendrites (Damlama and Tepper, 1992, 1993). These facts suggest that after blockade of the collateral GABAergic input from pars reticulata to pars compacta, stimulation of thalamus or superior colliculus may evoke a polysynaptic excitation of dopaminergic neurons mediated through the subthalamic nucleus. This is presumably not observed under control conditions because it is masked by a near simultaneous $\mathrm{GABA}_{\mathrm{A}}$ inhibition arising from excitation of pars reticulata neurons.

Bicuculline also produced marked increases in the proportion of neurons firing in the bursty mode and in the proportion of spikes fired in bursts, and concomitant decreases in the proportion of neurons firing in the pacemaker and random modes. In contrast, 2-hydroxysaclofen did not increase the proportion of neurons firing in the bursty mode or the proportion of spikes fired in bursts, but rather produced a modest increase in the proportion of neurons firing in the pacemaker mode, and an increase in the regularity of the firing. A similar shift in the distribution of firing patterns was obtained by kainate lesions of the globus pallidus. In contrast, others have reported that intravenous administration of the CGP 35348, another $\mathrm{GABA}_{B}$ antagonist, did not affect either the firing rate or pattern of dopaminergic neurons, whereas baclofen, a $\mathrm{GABA}_{\mathrm{B}}$ agonist reduced the firing rate and regularized the firing pattern (Engberg et al., 1993). We cannot fully account for the discrepancy between the two sets of results, but application of drugs by diffusion through the recording micropipette results in a very discrete locus of action, far more restricted than intravenous and likely more restricted than iontophoretic application. Since pars reticulata neurons also respond to $\mathrm{GABA}_{\mathrm{B}}$ agonists and antagonists, it is likely that the effects of intravenous drug administration result from a combination of direct effects on the dopaminergic neuron plus indirect effects mediated through pars reticulata neurons.

Our results suggest that the GABAergic inputs to dopaminergic neurons, arising from the projection neurons of the sub- 


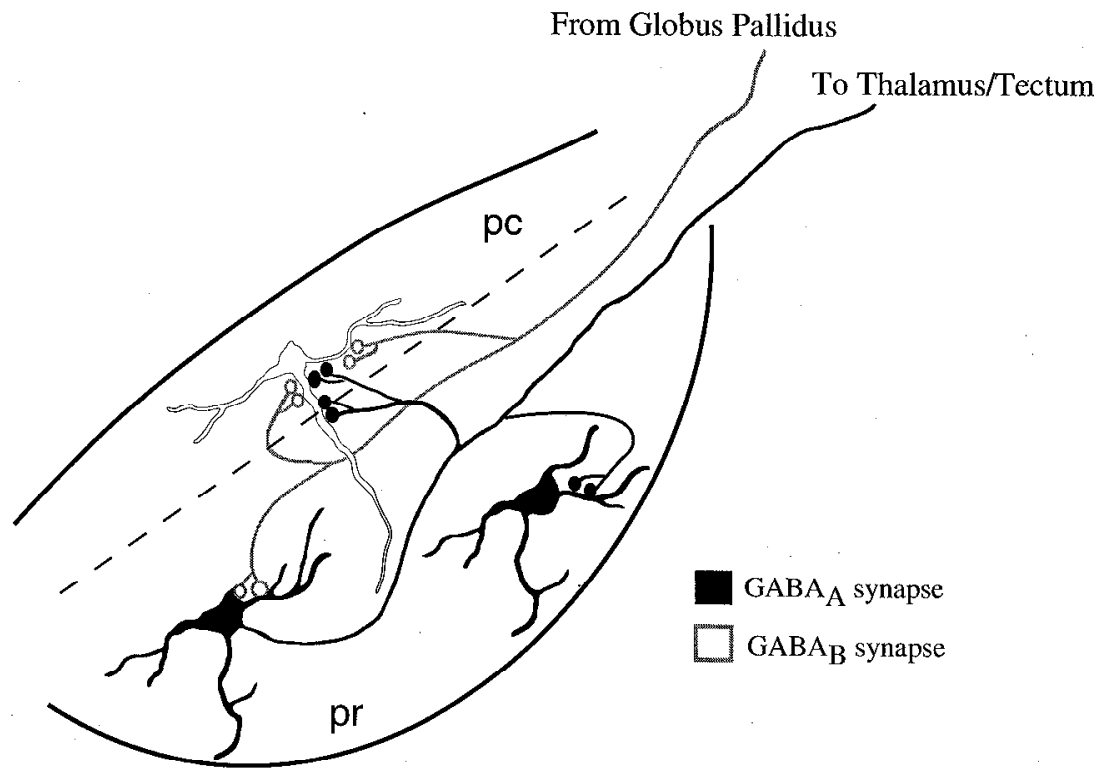

Figure 9. Simplified schematic diagram illustrating proposed model of differential sources of inputs to GA$\mathrm{BA}_{\mathrm{A}}$ and $\mathrm{GABA}_{\mathrm{B}}$ receptors on nigrostriatal neurons. Synapses made by axon collaterals of pars reticulata $\mathrm{GA}$ BAergic projection neurons selectively access GABA receptors while those made by descending GABAergic projections from globus pallidus access $\mathrm{GABA}_{\mathbf{b}}$ receptors.

stantia nigra pars reticulata and those arising from the globus pallidus (and possibly the neostriatum), are pharmacologically and functionally distinct. Those arising from the collaterals of the pars reticulata projection neurons form synapses that access primarily or exclusively $\mathrm{GABA}_{\mathrm{A}}$ receptors, while those descending from globus pallidus form synapses that access primarily or exclusively $\mathrm{GABA}_{\mathrm{B}}$ receptors, as illustrated schematically in Figure 9.

There is precedent for an anatomically selective and dissociable action of $\mathrm{GABA}_{\mathrm{A}}$ and $\mathrm{GABA}_{\mathrm{B}}$ responses in the midbrain. Both $\mathrm{GABA}_{\mathrm{A}}$ and $\mathrm{GABA}_{\mathrm{B}}$ responses are seen in midbrain dopamine neurons in vitro (Lacey et al., 1988, 1993; Sugita et al., 1992; Hajós and Greenfield, 1993). However, only GABA $A_{A}$ responses occur spontaneously under conditions of high potassium suggesting that the cells giving rise to the projections that stimulated $\mathrm{GABA}_{\mathrm{B}}$ receptors were lost in the slice preparation whereas those giving rise to $\mathrm{GABA}_{\mathrm{A}}$ responses remained (Sugita et al., 1992). This interpretation of a local origin for the activation of $\mathrm{GABA}_{\mathrm{A}}$ receptors is reinforced by the observations that in vitro, application of $\mathrm{GABA}_{\mathrm{A}}$, but not $\mathrm{GABA}_{\mathrm{B}}$ antagonists, by themselves increased the firing of pars reticulata neurons (Rick and Lacey, 1994) and that a presynaptic action of GABA $A_{B}$ but not $\mathrm{GABA}_{\mathrm{A}}$ antagonists was observed on extrinsic afferents to substantia nigra (Cameron and Williams, 1993).

\section{Afferent control of dopaminergic neuron firing pattern}

Dopaminergic neurons recorded in vivo have long been recognized to fire spontaneously in one of three patterns; pacemakerlike firing, a random, single spike mode, or in a bursty mode (Bunney et al., 1973; Wilson et al., 1977; Grace and Bunney, 1984), with the random mode predominating in vivo. The bursts consist of a cluster of up to 12 spikes successively decreasing in amplitude and increasing in interspike interval in anesthetized rats, although longer bursts have been reported in freely moving animals (Grace and Bunney, 1984). Single neurons are known to switch spontaneously from one mode to another (e.g., Freeman et al., 1985). In actuality, these three patterns can be considered to represent the two extremes and the middle of a continuum of firing pattern. In vitro, however, virtually all nigral dopaminergic neurons fire in a very regular, pacemaker-like pat- tern, and bursting does not occur (Grace, 1987). This suggests that burst firing is triggered somehow by afferent input.

While it is clear that excitatory amino acid afferents, and in particular NMDA inputs (e.g., Grace and Bunney, 1984; Charlety et al., 1991; Johnson et al., 1992; Overton and Clark, 1992; Wang and French, 1992), may play a role in the control of dopaminergic neuron firing rate and the generation of bursty firing, the present data also indicate quite clearly that changes in GA$\mathrm{BA}_{\mathrm{A}}$ and $\mathrm{GABA}_{\mathrm{B}}$ inputs can differentially affect firing pattern. These data have led us to propose the following simplified model of the in vivo modulation of firing pattern of substantia nigra dopaminergic neurons.

When striatonigral neurons fire, they cause a brief interruption in the tonic firing of pars reticulata GABAergic projection neurons. This is translated via the axon collaterals of the reticulata projection neurons into a brief disinhibition of the dopaminergic neurons as the $\mathrm{GABA}_{\mathrm{A}}$ input stops momentarily, producing rapid depolarization of the dopaminergic neuron which leads to a burst, perhaps due to the activation of a LTS (e.g., Llinás et al., 1984; Grace and Bunney, 1985). Conversely, activation of striatopallidal neurons produces a brief cessation of firing of pallidonigral neurons that leads to a disinhibition of $\mathrm{GABA}_{\mathrm{B}}$ input to the dopaminergic neuron producing a slower depolarization that inactivates the LTS and hence does not produce a burst, but simply leads to increased single spike or pacemaker-like firing. In this way the firing pattern of dopaminergic neurons is toggled between bursty and random or pacemaker-like firing by the complementary activity of the two striatal output pathways.

Support for this model is given by the natural firing pattern of neostriatal medium spiny neurons in vivo. Although neostriatal neurons exhibit relatively low mean spontaneous firing rates, their firing pattern is highly episodic, and dependent on membrane potential which fluctuates between "enabled" and "disabled" states (Wilson and Groves, 1981; Wilson, 1993). Medium spiny neurons fire only during the enabled state, which lasts from a few hundred to a few thousand milliseconds (Wilson, 1993), and during this time, their target cells in globus pallidus and substantia nigra pars reticulata are efficiently inhibited (Wilson, 1990). This would translate into periods of similar duration in dopaminergic neurons of bursting or regular firing depending 
on whether pars reticulata or globus pallidus neurons are the major recipients of the striatal output. The frequency of occurrence and the duration of the periods of bursting in dopaminergic neurons previously reported are similar to those of the enabled state of neostriatal neurons.

The pars reticulata is the site of termination of the vast majority of afferents to the substantia nigra and in this region, most afferents synapse preferentially on nondopaminergic dendrites. This is true not only for the GABAergic inputs from the neostriatum but also for the major excitatory inputs from subthalamic nucleus, pedunculopontine nucleus (Damlama and Tepper, 1992, 1993), and prefrontal cortex (Sesack and Pickel, 1992). In contrast to dopaminergic neurons (see, for example, Nakamura et al., 1979; Gariano and Groves, 1988; Smith and Grace, 1992), pars reticulata GABAergic neurons consistently respond to stimulation of cortex or subthalamus with excitation and/or increased firing (Nakanishi et al., 1987; Fujimoto and Kita, 1992). Since it has been estimated that between $70-90 \%$ of all synapses on dopaminergic neurons are GABAergic (Ribak et al., 1976, 1980; Smith and Bolam, 1989, 1990), it appears that nigral dopaminergic neurons, like the targets of basal ganglia output neurons in the thalamus and superior colliculus (e.g., Chevalier and Deniau, 1990), are modulated in an important way through disinhibition, and that the GABAergic projection neurons of the pars reticulata are the principal mediators of this disinhibition.

\section{References}

Anderson DR, Li W, Tepper JM (1993) GABAergic inhibition of nigrostriatal dopaminergic neurons by selective activation of pars reticulata projection neurons. Soc Neurosci Abstr 19:1432.

Bolam JP, Smith Y (1990) The GABA and substance P input to dopaminergic neurons of the substantia nigra of the rat. Brain Res 529: $57-78$.

Braszko JJ, Bannon MJ, Bunney BS, Roth RH (1981) Intrastriatal kainic acid: acute effects on electrophysiological and biochemical measures of nigrostriatal dopaminergic activity. J Pharmacol Exp Ther 216:289-293.

Bunney BS, Walters JR, Roth RH, Aghajanian GK (1973) Dopaminergic neurons: effect of antipsychotic drugs and amphetamine on singlc ccll activity. J Pharmacol Exp Ther 185:560-571.

Cameron DL, Williams JT (1993) Dopamine D1 receptors facilitate transmitter release. Nature 366:344-347.

Carter DA, Fibiger HC (1978) The projections of the entopeduncular nucleus and globus pallidus in the rat as demonstrated by autoradiography and horseradish peroxidase histochemistry. J Comp Neurol 177:113-124.

Charlety PJ, Grenhoff J, Chergui K, De La Chapelle BU, Svensson TH, Chouvet $G$ (1991) Burst firing of mesencephalic dopamine neurons is inhibited by somatodendritic application of kynurenate. Acta Physiol Scand 142:105-112.

Chevalier G, Deniau JM (1990) Disinhibition as a basic process in the expression of striatal function. Trends Neurosci 13:277-280.

Collingridge GL, James TA, MacLeod NK (1980) Antidromic latency variations of nigral compacta neurones. Experientia 36:970-971.

Creese I, Burt DR, Snyder SH (1976) Dopamine receptor binding predicts clinical and pharmacological potencies of antischizophrenic drugs. Science 192:481-483.

Damlama M, Tepper JM (1992) Subthalamic and pedunculopontine inputs to the substantia nigra: a double label EM study. Soc Neurosci Abstr 18:809.

Damlama M, Tepper JM (1993) Subcortical excitatory inputs to nigral dopaminergic and non-dopaminergic neurons: a light and electron microscopic study. In: Proceedings of the 51st annual meeting of the Microscopy Society of America (Bailey GW, Rieder CL, eds), pp 94 95. San Francisco: San Francisco Press.

Damlama M, Bolam JP, Tepper JM (1993) Axon collaterals of pars reticulata projection neurons synapse on pars compacta neurons. Soc Neurosci Abstr 19:1432.

Deniau JM, Hammond C, Riszk A, Feger J (1978) Electrophysiological properties of identified output neurons of the rat substantia nigra (pars compacta and pars reticulata): evidence for the existence of branched neurons. Exp Brain Res 32:409-422.

Deniau JM, Kitai ST, Donoghue JP, Grofova I (1982) Neuronal interactions in the substantia nigra pars reticulata through axon collaterals of the projection neurons. Exp Brain Res 47:105-113.

Ellaway PH (1977) An application of the cumulative sum technique (cusums) to neurophysiology. J Physiol (Lond) 265:1-2P.

Engberg G, Kling-Petersen T, Nissbrandt H (1993) GABA ${ }_{B}$-receptor activation alters the firing pattern of dopamine neurons in the rat substantia nigra. Synapse 15:229-238.

Francois C, Percheron G, Yelnik J, Heyner S (1979) Demonstration of the existence of small local circuit neurons in the Golgi-stained primate substantia nigra. Brain Res 127:160-164.

Freeman AS, Zhang J (1993) Electrophysiological effects of CCK peptides on substantia nigra pars reticulata neurons. Soc Neurosci Abstr 19:1373.

Freeman AS, Meltzer LT, Bunney BS (1985) Firing properties of substantia nigra dopaminergic neurons in freely moving rats. Life Sci 36:1983-1994.

Fujimoto K, Kita H (1992) Responses of rat substantia nigra pars reticulata units to cortical stimulation. Neurosci Lett 142:105-109.

Fuller JH, Schlag JD (1976) Determination of antidromic excitation by the collision test: problems of interpretation. Brain Res 112:238-298.

Gariano RF, Groves PM (1988) Burst firing in midbrain dopamine neurons by stimulation of the medial prefrontal and anterior cingulate cortices. Brain Res 462:194-198.

Grace AA (1987) The regulation of dopamine neuron activity as determined by in vivo and in vitro intracellular recordings. In: Neurophysiology of dopaminergic systems-current status and clinical perspectives (Chiodo LA, Freeman AS, eds), pp 1-66. Detroit: Lakeshore.

Grace AA, Bunney BS (1979) Paradoxical GABA excitation of nigral dopaminergic cells: indirect mediation through reticulata inhibitory neurons. Eur J Pharmacol 59:211-218.

Grace AA, Bunney BS (1984) The control of firing pattern in nigral dopamine neurons: burst firing. J Neurosci 4:2877-2890.

Grace AA, Bunney BS (1985) Opposing effects of striatonigral feedback pathways on midbrain dopaminergic cell activity. Brain Res $333: 271-284$

Grace AA, Hommer DW, Bunney BS (1980) Peripheral and striatal influences on nigral dopamine cells: mediation by reticulata neurons. Brain Res Bull 5:105-109.

Grofová I (1975) Identification of striatal and pallidal neurons projecting to substantia nigra. An experimental study by means of retrograde transport of horseradish peroxidase. Brain Res 91:286-291.

Grofová I, Fonnum F (1982) Extrinsic and intrinsic origin of GAD in pars compacta of the rat substantia nigra. Soc Neurosci Abstr 8:961.

Grofová I, Deniau JM, Kitai ST (1982) Morphology of the substantia nigra pars reticulata projection neurons intracellularly labeled with HRP. J Comp Neurol 208:352-368.

Groves PM, Wilson CJ, MacGregor RJ (1978) Neuronal interactions in the substantia nigra revealed by statistical analysis of spike trains. In: Interactions between putative neurotransmitters (Garattini S, Pujol F, Samanin R, eds), pp 191-215. New York: Raven.

Gulley RL, Wood RL (1971) The fine structure of the neurons in the rat substantia nigra. Tissue Cell 3:675-680.

Guyenet PG, Aghajanian GK (1978) Antidromic identification of dopaminergic and other output neurons of the rat substantia nigra. Brain Res 150:69-84.

Hajós M, Greenfield SA (1993) Topographic heterogeneity of substantia nigra neurons: diversity in intrinsic membrane properties and synaptic inputs. Neuroscience 55:919-934.

Hajós M, Greenfield SA (1994) Synaptic connections between pars compacta and pars reticulata neurones: electrophysiological evidence for functional modules within the substantia nigra. Brain Res 660: 216-224.

Harnois C, Filion M (1980) Pallidal neurons branching to the thalamus and to the midbrain in the monkey. Brain Res 186:222-225.

Hattori T, Fibiger HC, McGeer PL (1975) Demonstration of a pallidonigral projection innervating dopaminergic neurons. J Comp Neurol 162:487-504.

Johnson SW, North RA (1992) Opioids excite dopamine neurons by hypcrpolarization of local interncurons. J Ncurosci 12:483-488.

Johnson SW, Seutin V, North RA (1992) Burst firing in dopaminergic 
neurons induced by $N$-methyl-D aspartate: role of electrogenic sodium pump. Science 258:665-667.

Juraska JM, Wilson CJ, Groves PM (1977) The substantia nigra of the rat: a Golgi study. J Comp Neurol 172:585-599.

Kalivas PW (1993) Neurotransmitter regulation of dopamine neurons in the ventral tegmental area. Brain Res Rev 18:75-113.

Kang Y, Kitai ST (1993) Calcium spike underlying rhythmic firing in dopaminergic neurons of the rat substantia nigra. Neurosci Res 18: 195-207.

Kita T, Kita H, Kitai ST (1986) Electrical membrane properties of rat substantia nigra neurons in an in vitro slice preparation. Brain Res $372: 21-30$

Laccy MG (1993) Ncurotransmitter receptors and ionic conductances regulating the activity of neurones in substantia nigra pars compacta and ventral tegmental area. In: Progress in brain research, Vol 99, Chemical signalling in the basal ganglia (Arbuthnott GW, Emson PC, eds), pp 251-276. Amsterdam: Elsevier.

Lacey MG, Mercuri NB, North RA (1988) On the potassium conductance increase activated by $\mathrm{GABA}_{\mathrm{B}}$ and dopamine $\mathrm{D}_{2}$ receptors in rat substantia nigra neurones. J Physiol (Lond) 401:437-453.

Lacey MG, Mercuri NB, North RA (1989) Two cell types in rat substantia nigra zona compacta distinguished by membrane properties and the actions of dopamine and opioids. J Neurosci 9:1233-1241.

Llinas R, Greenfield SA, Jahnsen H (1984) Electrophysiology of pars compacta cells in the in vitro substantia nigra-a possible mechanism for dendritic release. Brain Res 294:127-132.

Matsuda Y, Fujimura K, Yoshida S (1987) Two types of ncurons in the substantia nigra pars compacta studied in a slice preparation. Neurosci Res 5:172-179.

Mereu G, Gessa GL (1985) Low doses of ethanol inhibit the firing of neurons in the substantia nigra pars reticulata: a GABAergic effect? Brain Res 360:325-330.

Myers JL (1972) Fundamentals of experimental design, 2nd ed, p 364. Boston: Allyn and Bacon.

Nakamura S, Iwatsubo K, Tsai C-T, Iwama K (1979) Cortically evoked inhibition of neurons of rat substantia nigra (pars compacta). Jpn $\mathbf{J}$ Physiol 29:353-357.

Nakanishi H, Kita H, Kitai ST (1987) Intracellular study of rat substantia nigra pars reticulata neurons in an in vitro slice preparation: electrical membrane properties and response to subthalamic stimulation. Brain Res 437:45-55.

Nedergaard S, Greenfield SA (1992) Sub-populations of pars compacta neurons in the substantia nigra: the significance of qualitatively and quantitatively distinct conductances. Neuroscience 48:423-437.

Nitsch C, Riesenberg R (1988) Immunocytochemical demonstration of GABAergic synaptic connections in rat substantia nigra after different lesions of the striatonigral projection. Brain Res $461: 12 ;-142$.

Overton P, Clark D (1992) Iontophoretically administered drugs acting and the $N$-methyl-M-aspartate receptor modulate burst firing in A9 dopamine neurons in the rat. Synapse 10:131-140.

Ribak CE, Vaughn JE, Saito K, Barber R, Roberts E (1976) Immunocytochemical localization of glutamate decarboxylase in rat substantia nigra. Brain Res 116:287-298.

Ribak CE, Vaughn JE, Roberts E (1980) GABAergic nerve terminals decrease in the substantia nigra following hemitransections of the striatonigral and pallidonigral pathways. Brain Res 192:413-420.

Rick CE, Lacey MG (1994) Rat substantia nigra neurones are tonically inhibited via $\mathrm{GABA}_{\mathrm{A}}$, but not $\mathrm{GABA}_{\mathrm{B}}$, receptors in vitro. Brain Res 659:133-137.

Santiago M, Westerink BHC (1992) The role of GABA receptors in the control of nigrostriatal dopaminergic neurons: dual probe microdialysis study in awake rats. Eur J Pharmacol 219:175-181.

Schwyn RC, Fox CA (1974) The primate substantia nigra: a Golgi and electron microscopic study. J Hirnforsch 15:95-126.

Sesack SR, Pickel VM (1992) Prefrontal cortical efferents in the rat synapse on unlabeled neuronal targets of catecholamine terminals in the nucleus accumbens septi and on dopamine neurons in the ventral tegmental area. J Comp Neurol 320:145-160.

Smith Y, Bolam JP (1989) Neurons of the substantia nigra reticulata receive a dense GABA-containing input from the globus pallidus in the rat. Brain Res 493:160-167.

Smith Y, Bolam JP (1990) The output neurones and the dopaminergic neurones of the substantia nigra receive a GABA-containing input from the globus pallidus in the rat. J Comp Neurol 296:47-64.

Smith ID, Grace AA (1992) Role of the subthalamic nucleus in the regulation of nigral dopamine neuron activity. Synapse 12:287-303.

Steward O, Tomasulo R, Levy WB (1990) Blockade of inhibition in a pathway with dual excitatory and inhibitory action unmasked a capability for LTP that is otherwise not expressed. Brain Res 516:292300.

Sugimoto T, Hattori T, Mizuno K, Satoh M (1983) Direct projections from the centre median-parafascicular complex to the subthalamic nucleus in the cat and rat. J Comp Neurol 214:209-216.

Sugita S, Johnson SW, North RA (1992) Synaptic inputs to GABA and $\mathrm{GABA}_{\mathrm{B}}$ receptors originate from discrete afferent neurons. Neurosci Lett 134:207-211.

Tepper JM, Nakamura S, Young SJ, Groves PM (1984) Autoreceptormediated changes in dopaminergic terminal excitability: effects of striatal drug infusions. Brain Res 309:317-333.

Tepper JM, Sawyer SF, Young SJ, Groves PM (1986) Intracellular recording and HRP staining of rat nigral neurons. Soc Neurosci Abstr $12: 1542$.

Tepper JM, Sawyer SF, Groves PM (1987) Electrophysiologically identified nigral dopaminergic neurons intracellularly labeled with HRP: light microscopic analysis. $J$ Neurosci 7:2794-2806.

Tepper JM, Trent F, Nakamura S (1990) Postnatal development of the electrical activity of rat nigrostriatal dopaminergic neurons. Dev Brain Res 54:21-33.

Tokuno H, Takada M, Ikai Y, Mizuno N (1994) Direct projections from the deep layers of the superior colliculus to the subthalamic nucleus in the rat. Brain Res 639:156-160.

Wang T, French ED (1993) L-Glutamate excitation of A10 dopamine neurons is preferentially mediated by activation of NMDA receptors: extra- and intracellular electrophysiological studies in brain slices. Brain Res 627:299-306.

Wilson CJ (1990) Basal ganglia. In: The synaptic organization of the brain, 3d ed (Shepherd G, ed), pp 279-316. New York: Oxford UP.

Wilson CJ (1993) The generation of natural firing patterns in neostriatal neurons. In: Progress in brain research, Vol 99, Chemical signalling in the basal ganglia (Arbuthnott GW, Emson PC, eds), pp 277-298. Amsterdam: Elsevier.

Wilson CJ, Groves PM (1981) Spontaneous firing patterns of identified spiny neurons in the rat neostriatum. Brain Res 220:67-80.

Wilson CJ, Young SJ, Groves PM (1977) Statistical properties of neuronal spike trains in the substantia nigra: cell types and their interactions. Brain Res 36:243-260.

Yoshida M, Precht W (1971) Monosynaptic inhibition of neurons of the substantia nigra by caudato-nigral fibers. Brain Res 32:225-228.

Yung WH, Häusser MA (1993) Evoked and spontaneous inhibitory postsynaptic potentials in guinea-pig substantia nigra dopaminergic neurones in vitro. J Physiol (Lond) 459:431P.

Yung WH, Häusser MA, Jack JJB (1991) Electrophysiology of dopaminergic and non-dopaminergic neurones of the guinea-pig substantia nigra pars compacta in vitro. J Physiol (Lond) 436:643-667.

Zhang J, Chiodo LA, Freeman AS (1992) Electrophysiological effects of MK-801 on rat nigrostriatal and mesoaccumbal dopaminergic neurons. Brain Res 590:153-163.

Zhang J, Chiodo LA, Freeman AS (1993) Effects of phencyclidine, MK-801 and 1,3-di(tolyl)guanidine on non-dopaminergic midbrain neurons. Eur J Pharmacol 230:371-374. 